\title{
Research on Safety and Static-Dynamic Legibility of Distressed Pavement
}

\author{
Chengyuan Mao, ${ }^{1}$ Yiming Bie, ${ }^{2}$ Yulong Pei, ${ }^{3}$ and Weiwei $\mathbf{Q i}^{2}$ \\ ${ }^{1}$ College of Engineering, Zhejiang Normal University, Jinhua, Zhejiang 321004, China \\ ${ }^{2}$ School of Traffic Science and Engineering, Harbin Institution of Technology, Harbin, Heilongjiang 150090, China \\ ${ }^{3}$ College of Traffic, Northeast Forestry University, Harbin, Heilongjiang 150040, China \\ Correspondence should be addressed to Yiming Bie; yimingbie@126.com
}

Received 18 July 2014; Accepted 13 September 2014

Academic Editor: Yongjun Shen

Copyright (C) 2015 Chengyuan Mao et al. This is an open access article distributed under the Creative Commons Attribution License, which permits unrestricted use, distribution, and reproduction in any medium, provided the original work is properly cited.

\begin{abstract}
In order to study the impacts of distressed pavement on driving safety, the drivers' driving behavior and driving characteristics need to be analyzed. By analyzing the drivers' characteristics, driving behavior' and braking characteristics of vehicles, relation between static legibility distance of the distressed pavement under different driving conditions and dynamic legibility distance during driving is revealed via statistical analysis. The relation between vehicle speeds, braking performance, and the minimum safety legibility distance is developed. The recommended static legibility distances for different speed limits are proposed, which would be useful to improve the driving safety under adverse road conditions.
\end{abstract}

\section{Introduction}

With the rapid growth of the economy and motorization, road construction has obtained unprecedented development while road mileage and density increase rapidly. In the conditions that facilities and technologies of road maintenance are more and more mature, and the materials are increasingly sophisticated, the road conditions are significantly improved. However, distress in pavement is inevitable due to the limited service life of the pavement, overloading of vehicles, and the quality of pavement. Besides, restricted by practical construction conditions, the distressed pavement cannot be repaired all at once. Therefore, distressed pavements are widespread in the cities with a great quantity beyond imagination. Damage of manhole covers, potholes, and settlement can be seen everywhere in the Chinese cities.

In daily life, people may pay more attention to factors which directly trigger traffic accidents since the damage of vehicles, casualties, and economic losses they caused are direct and obvious. Therefore, it is indeed worthy of research and attention $[1,2]$. On the other hand there is also another initial factor which may induce traffic accident, reduce traffic capacity, and affect the normal operation of the driver and driving comfort. That is the distress of the pavement widespread in the road. This may not be the most common factors leading to traffic accidents, but their adverse effects cannot be disregarded [3, 4]. The road capacity can be severely reduced by the deceleration or evasion of the vehicles due to the distress of the pavement in a road section with heavy traffic and other damage (such as the increase of the abrasion of tires, energy consumption, and emissions). The physiological and psychological damage to the drivers and the indirect loss (such as drivers' time loss) may be much more than those of one fatal traffic accident which may be even far beyond our imagination.

According to certain analysis, in the traffic accident, the error of observation, misjudgment, error of action, and other errors, respectively, account for 54\%, 54\%, 36\%, and $1 \%$; namely, the accidents resulting from the error of observation account for more than a half of the whole accidents. From this point the study on legibility during driving is the basis of the study on drivers' characteristics and behaviors [5].

Drivers will receive varied stimulations from all kinds of traffic information. The main part of the traffic information which is more than $80 \%$ is obtained by vision. Drivers need to sense the traffic condition quickly and accurately, identify 
initial objectives, predict the development and consequence of the traffic condition, and take proper measures to guarantee the safety of driving under the complex traffic conditions $[6,7]$. The psychological mood of the drivers during driving will be influenced by traffic condition and the state of their mind: on the one hand, positive and peaceful mind can remit the driving fatigue while negative mind is more likely to induce anger and tension which will consequently trigger adventure or aggressive driving behaviors; on the other hand, psychological burden of drivers will be increased by bad traffic condition [8].

Since distressed pavement will adversely affect the operation of the vehicles, researches on the recognition, classification, and influence of the distress in pavement are conducted by different scholars. Grivas et al. $[9,10]$ put forward an analysis method based on fuzzy set theory which can be used to determine single index of the pavement damage from several indexes. Different levels of pavement distress are qualitatively described; the value of the distress is expressed through membership function and quantified via the input of road maintenance specialist. Prozzi and Hong [11] established an axle load distribution optimization function, put forward a comprehensive statistical method based on road load, and described the observed axial load by using the mixed lognormal distribution. Khan [12] established an identification manual of the distressed pavement in Pakistan which provided the method to obtain consistent, repeatable, and a large deal of data on pavement distress. It can be an advanced basic reference book on pavement management system which is involved in the deterioration trend analysis and evaluation of motor vehicle traffic, Pakistan, 2006, and at the same time provides quantitative information for the repairing scope of distressed pavement. Karan et al. [13] described the relationship between average speeds of vehicles and the condition of the pavement for two-lane highway: pavement irregularities were chosen to be the evaluation parameters of the pavement condition, 72 of survey sections were selected according to the pavement irregularities, traffic capacity and saturation were calculated, and then comfort index, saturation, and the speed limit were chosen as control index; thus regression model between the average speed of vehicles and the pavement irregularities was established.

Scholars have also made some progress on the research in traffic operation and traffic capacity under the condition of distressed pavement. For example, Gallegos López et al. [14] recorded the information of road profile and introduced international roughness index to evaluate the condition of the pavement; the international pavement roughness index was absorbed into the formula of road capacity and LOS (level of service) in HCM2000 as a corrected parameter; thus a new formula considering the influence of both lane width and pavement roughness on road capacity was established; the correction parameters were obtained by fitting to actual statistical data collected in Mexico and tested by actual cases. Chandra [15] analyzed the influence of pavement irregularities on the road capacity and relation model between road capacity and pavement irregularities was established via analyzing the data of pavement irregularities, free stream velocity, and the proportion of middle-sized vehicles. Johnnie and Neil [16] analyzed the traffic stream characteristics when roads were under maintenance and construction: the impact of some lanes under long-term or short-term construction on the traffic flow was investigated; the relation between vehicle speed and density was studied and all the researches indicate that road maintenance and construction have great impact on the parameters of traffic flow [17].

In conclusion, the research on the generation of pavement distress and pavement maintenance is numerous. But the research on the relation between static and dynamic legibility of pavement distress and safety which is the base of the research on driving behavior and traffic flow is very few. Therefore, based on experimental investigation, using regression analysis method, by means of theory analysis, the internal relation between pavement distresses, legibility, driving behavior, and driving safety is revealed and the theory of driving behaviors under pavement distress is perfected. The follow-up arrangement of this paper is as follows:

(1) survey on legibility distance of distressed pavement;

(2) relation between static and dynamic legibility of distressed pavement;

(3) analysis on the safety legibility of distressed pavement.

\section{Survey on Legibility Distance of Distressed Pavement}

2.1. Legibility of Pavement Distress and Its Influencing Factors. In order to study whether pavement distress is easy to be noticed or not or whether it has significant influence on drivers' operation, the concept of legibility of pavement distress is introduced.

Just as the static vision and dynamic visual of the human being, legibility of pavement distress can also be divided into static legibility $\left(L_{s}\right)$ and dynamic legibility $\left(L_{d}\right) . L_{s}$ refers to the complexity for drivers to recognize the pavement distress when the speed of the vehicle is extremely slow or even zero and the distance between the driver and the pavement distress is stable while $L_{d}$ refers to the complexity for drivers to recognize the pavement distress in the process of driving when the distance between the driver and the pavement distress keeps changing. $L_{d}$ can be measured by the distance between the eyes of the observer and the pavement distress as $L_{s}$. Corresponding with static legibility and dynamic legibility, legibility distance can be divided into static legibility distance $\left(D_{s}\right)$ and dynamic legibility distance $\left(D_{d}\right)$. Existing research indicates that human eyesight will be reduced with the increase of the travelling speed; therefore dynamic legibility is weaker than static legibility and is getting weaker with the speed increasing.

According to Yaling Guo et al. studies, the main influencing factors of legibility mainly include the visual angle of the eyes, color contrast surrounding the objects, and the displacement of the object relative to the observer's eyes. The visual angle of the observer's eyes on the objects is determined by the size of the objects and the distance between the observer's eyes and the objects as shown in Figure 1; 
TABLE 1: The investigation results of pavement distress.

\begin{tabular}{|c|c|c|c|c|c|c|c|}
\hline Number & Location $^{(1)}$ & Road level $^{2}$ & Length $\left(10^{-2} \mathrm{~m}\right)$ & Width $\left(10^{-2} \mathrm{~m}\right)$ & $D_{s}(\mathrm{~m})$ & $D_{d}(\mathrm{~m})$ & $v(\mathrm{~km} / \mathrm{h})$ \\
\hline 1 & Huang He & $\mathrm{b}$ & 108 & 102 & 94.8 & 73.7 & 41.2 \\
\hline 2 & Huang $\mathrm{He}$ & $\mathrm{b}$ & 122 & 178 & 88.0 & 63.8 & 41.5 \\
\hline 3 & Wenchang & $\mathrm{b}$ & 92 & 88 & 94.8 & 75.4 & 26.3 \\
\hline 4 & Wenchang & $\mathrm{b}$ & 37 & 32 & 24.3 & 18.2 & 23.6 \\
\hline 5 & Wenchang & $\mathrm{b}$ & 163 & 62 & 66.3 & 43.5 & 35.2 \\
\hline 6 & Jiaohua & $\mathrm{b}$ & 125 & 135 & 43.6 & 25.6 & 18.1 \\
\hline 7 & Xidazhi & $\mathrm{b}$ & 145 & 76 & 79.5 & 59.5 & 36.6 \\
\hline 8 & Hexing & $\mathrm{a}$ & 88 & 98 & 97.5 & 75.4 & 47.6 \\
\hline 9 & Hexing & $\mathrm{a}$ & 126 & 120 & 106.6 & 91.1 & 34.9 \\
\hline 10 & Jinxiang & $\mathrm{b}$ & 110 & 104 & 71.9 & 49.2 & 29.9 \\
\hline 11 & Jinxiang & $\mathrm{b}$ & 55 & 45 & 33.2 & 20.5 & 32.4 \\
\hline 12 & Gongbin & $\mathrm{b}$ & 113 & 96 & 65.4 & 51.5 & 25.1 \\
\hline 13 & Hanshui & c & 88 & 56 & 56.4 & 44.1 & 18.1 \\
\hline 14 & Hongxiang & c & 106 & 121 & 66.2 & 45.6 & 34.0 \\
\hline 15 & Zhongshan & $\mathrm{b}$ & 114 & 102 & 86.1 & 61.7 & 38.3 \\
\hline 16 & Zhongshan & $\mathrm{b}$ & 90 & 90 & 37.6 & 22.5 & 32.6 \\
\hline 17 & Xuan Qiang & $\mathrm{d}$ & 64 & 114 & 43.1 & 23.3 & 19.8 \\
\hline 18 & Lujia & d & 210 & 150 & 102.9 & 84.2 & 24.3 \\
\hline 19 & Pinggong & d & 42 & 34 & 30.8 & 20.3 & 19.5 \\
\hline 20 & Pinggong & $\mathrm{d}$ & 44 & 30 & 24.6 & 18.4 & 25.8 \\
\hline
\end{tabular}

Notes: ${ }^{1}$ road name.

(2) a: expressway; b: trunk road; c: secondary road; d: branch.

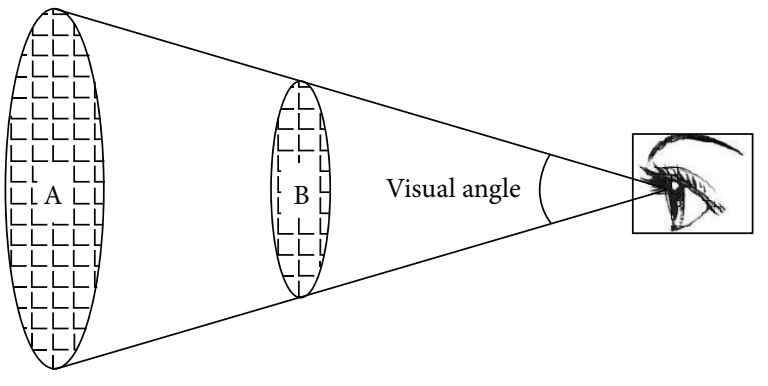

FIgURE 1: The visual angle of the eyes.

the visual angle on object $\mathrm{A}$ is the same to that on object $\mathrm{B}$; then the legibility of them is the same although $\mathrm{A}$ is bigger than B $[18,19]$.

2.2. Investigation on Legibility Distance of Distressed Pavement. The main factors influencing the legibility distance of distressed pavement are the size of the distress, the location of the distress, drivers' characteristics and vehicle speed, and so forth. Therefore, the survey is conducted aiming at these factors.

Investigation on the size of pavement distress: 20 pavement distresses on expressway, trunk road, secondary road, and branch in Harbin are selected and the extents of the damage (size of the distresses) are measured.

Investigation on static legibility distance $\left(D_{s}\right)$ of distressed pavement: 4 types of drivers including male novice drivers, male skilled drivers, female novice drivers, and female skilled drivers are chosen as respondents and the legibility distances of distressed pavement selected are investigated. CVA (corrected visual acuity) of the respondents ranges from 1.0 to 1.2 and the heights of them range from $1.70 \mathrm{~m}$ to $1.74 \mathrm{~m}$. The legibility distances of the whole respondents are recorded and the average legibility distance is chosen to be the static legibility distance of the distressed pavement.

Investigation on dynamic legibility distance $\left(D_{d}\right)$ : the respondents were wearing I view X HED eye tracker which is made in Germany. All respondents have known the position of pavement distress. The investigators are driving a Santana 2000 car in the selected pavement sections, the eye tracker records the drivers' eyes track, and the vehicle data recorder records vehicle speed and vehicle's location. Survey with vehicle recorder and eye tracker is shown in Figure 2. The $D_{d}$ we collected is the average distance between driver's eyes and distressed pavement, when the driver found distressed pavement.

The survey result of legibility distance is shown in Table 1. Most legibility distance belongs to $20-100 \mathrm{~m}$, the average $D_{s}$ is $48.4 \mathrm{~m}$, and average $D_{d}$ is $65.7 \mathrm{~m}$; obviously, $D_{s}$ is longer than $D_{d}$.

\section{Relation Analysis on $D_{s}$ and $D_{d}$}

3.1. Analysis on Data Investigated. As the data investigated from 20 pavement distresses show,

(1) the range of static legibility distance is from $24.3 \mathrm{~m}$ to $106.6 \mathrm{~m}$ and the average is $65.7 \mathrm{~m}$; 


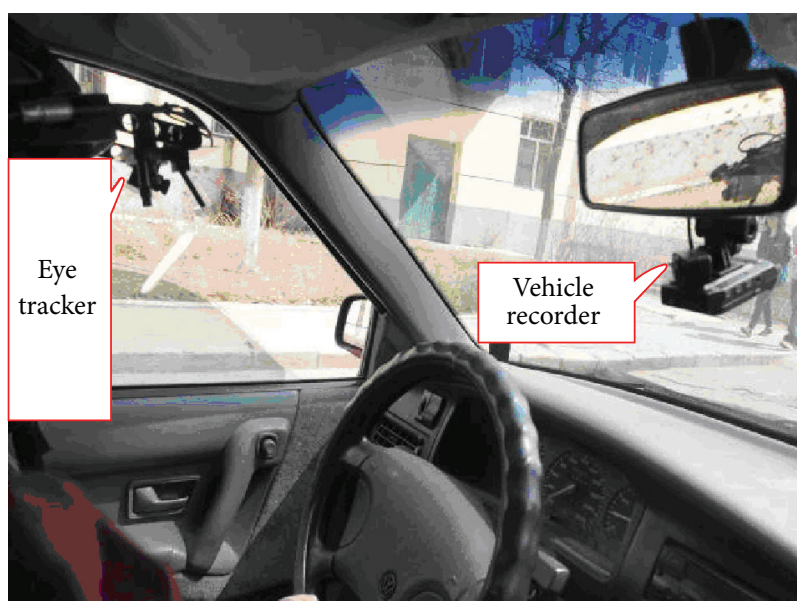

FIGURE 2: Survey with vehicle recorder and eye tracker.

(2) the range of dynamic legibility distance is from $18.2 \mathrm{~m}$ to $91.1 \mathrm{~m}$ and the average is $48.4 \mathrm{~m}$;

(3) the static legibility distance is much longer than the dynamic legibility distance in one distressed pavement which indicates that dynamic vision is weaker than static vision once again.

3.2. Relation Analysis on Static Legibility Distance $\left(D_{s}\right)$ and Dynamic Legibility Distance $\left(D_{d}\right)$. Existing research shows that dynamic legibility distance $\left(D_{d}\right)$ of the object is related to static legibility distance $\left(D_{s}\right)$ and the speed of the object $v$. Taking $D_{d}$ as the dependent variable and taking $D_{s}$ and $v$ as the independent variable, then

$$
D_{d}=0.9004 \cdot D_{s}-0.1968 \cdot v-4.7645 \text {, }
$$

where $D_{d}$ is the pavement distress's dynamic legibility, m; $D_{s}$ is the pavement distress's static legibility, $\mathrm{m} ; v$ is the vehicle's speed, $\mathrm{m} / \mathrm{s}$.

The relationship between $D_{d}$ and $D_{s}$ is shown in Figure 3. We can see a linear relationship between $D_{d}, D_{s}$, and $v$ (the correlation coefficient was 0.9851 ; the standard error was 3.8120).

If $D_{s} \in(0,100), v \in(0,100)$, then we can get the relationship between $D_{d}, D_{s}$, and $v$, shown in Figure 4 . The results indicated that $D_{d}$ increased with the raising of $D_{s}$ and diminishes with $v$. So, if we want to increase $D_{d}$, we could set a speed limit and increase the value of $D_{s}$.

\section{Analysis on Safety Legibility of Distressed Pavement}

4.1. Basic Legibility Rules. When the driver notices the pavement distress, he/she would judge if or not the pavement distress has a negative effect, and then he/she will decide how to drive, for example, gazing at the pavement distress and paying attention to the position of the vehicle. The worse the legibility of pavement distress is and the greater the distress is, the longer the fixation time can be.

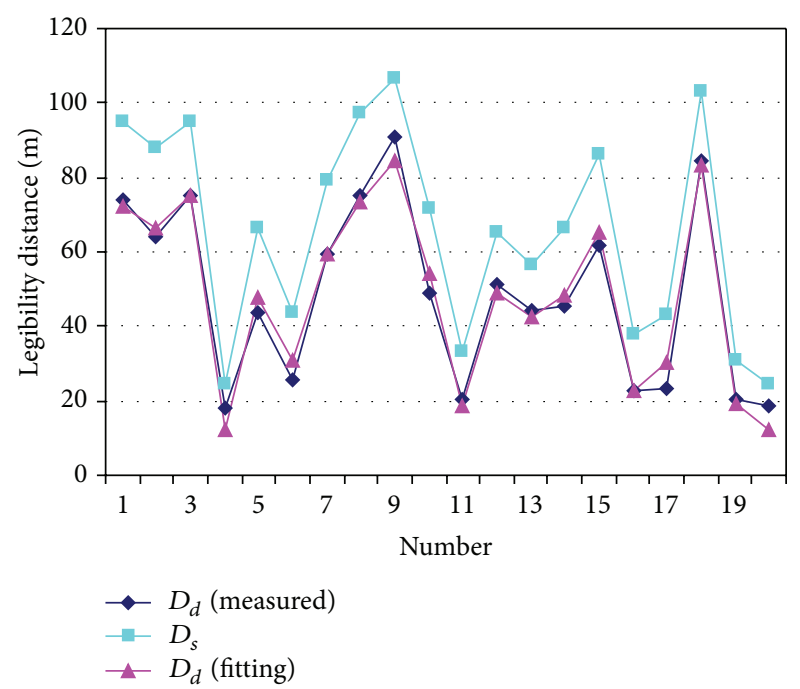

Figure 3: Analysis of relationship between $D_{d}$ and $D_{s}$.

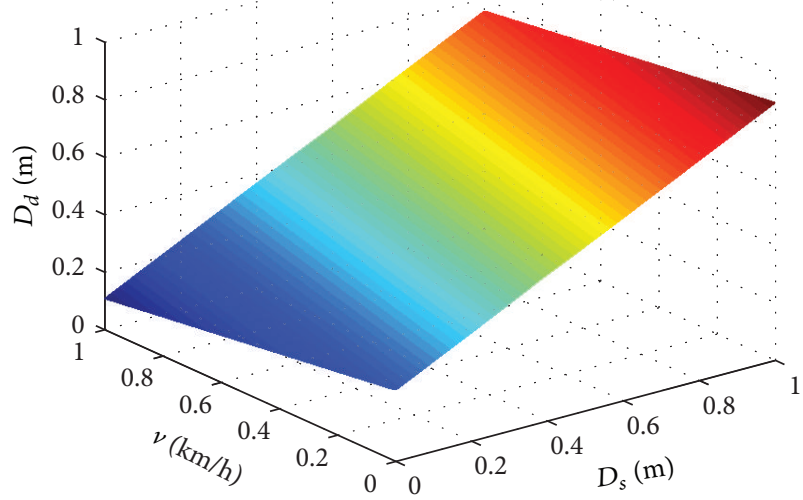

FIgure 4: Relation analysis on $D_{d}, D_{s}$, and $v$.

In order to judge the probable damage caused by the pavement distress, the drivers still need to constantly collect driving information by watching, listening, and touching. When the vehicle is approaching the pavement distress, the driver will pay more and more attention to it; in particular when the vehicle is 5-20 meters away from the pavement distress, the driver will always gaze at it till pass the distressed pavement as shown in Figure 5.

\subsection{Safety Legibility Distance Analysis}

4.2.1. The Minimum Safety Distance. The minimum safety distance $\left(D_{\min 1}\right)$ refers to the safe distance to front vehicle or obstacle when vehicle suddenly brakes from $100 \mathrm{~km} / \mathrm{h}$ to 0 in an emergency, which can be expressed as follows:

$$
D_{\min 1}=-0.5 \cdot \frac{v^{2}}{a}+d,
$$

where $D_{\min 1}$ is the minimum safety distance, $\mathrm{m}$; $a$ is acceleration of the vehicle, acceleration $a>0$, deceleration $a<0$, 
TABLE 2: $D_{\min 1}$ in different speed conditions.

\begin{tabular}{lccccc}
\hline Number & $v(\mathrm{Km} / \mathrm{h})$ & $v(\mathrm{~m} / \mathrm{s})$ & Brake time $(\mathrm{s})$ & Brake distance $(\mathrm{m})$ & $D_{\min 1}(\mathrm{~m})$ \\
\hline 1 & 20 & 5.56 & 0.74 & 2.06 & 4.63 \\
2 & 30 & 8.33 & 1.11 & 8.23 & 9.63 \\
3 & 40 & 11.11 & 1.48 & 12.86 & 13.23 \\
4 & 50 & 13.89 & 1.85 & 18.52 & 25.21 \\
5 & 60 & 16.67 & 2.22 & 32.92 & 30.21 \\
6 & 70 & 19.44 & 2.59 & 41.67 & 37.92 \\
7 & 80 & 22.22 & 2.96 & 51.44 & 46.67 \\
8 & 90 & 25.00 & 3.33 & 3.70 & 56.44 \\
\hline
\end{tabular}

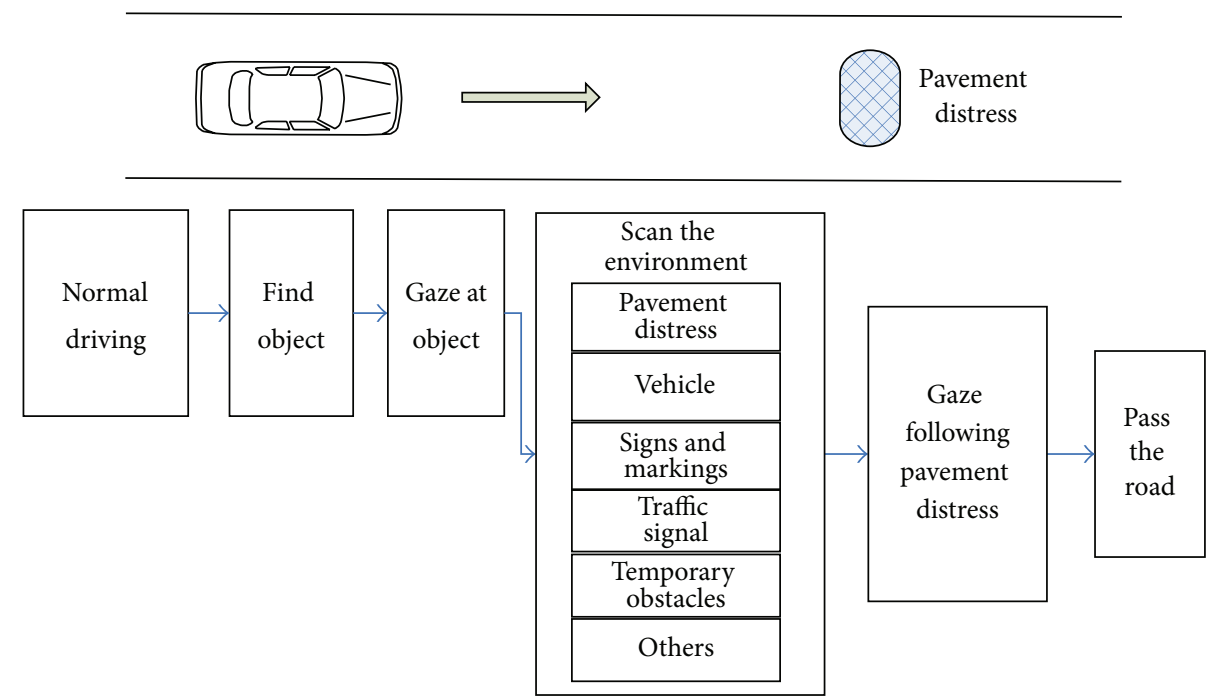

Figure 5: The drivers' observation process of pavement distress.

emergency braking $a$ belongs to $-7.5 \mathrm{~m} / \mathrm{s}^{2} \sim-10 \mathrm{~m} / \mathrm{s}^{2}$, and $a=-7.5 \mathrm{~m} / \mathrm{s}^{2}$ in this paper. $d$ is safe stopping distance, at most $d=2 \sim 5 \mathrm{~m}$ in general, and $d=5 \mathrm{~m}$ in this paper.

According to formula (2), we can see that the better the vehicle braking performance is, the shorter the $D_{\min 1}$ is. Thus we can get $D_{\min 1}$ in all speed conditions, as shown in Table 2 .

The legal requirement of automobile (nonload) braking distance in China is as follows.

(1) The braking distance of a passenger service vehicle with no more than 9 seats must be shorter than $19 \mathrm{~m}$ when its initial velocity is $50 \mathrm{~km} / \mathrm{h}$.

(2) The braking distance of a truck with a total mass less than $4.5 \mathrm{t}$ must be shorter than $21 \mathrm{~m}$ when its initial velocity is $50 \mathrm{~km} / \mathrm{h}$.

(3) The braking distance of the other cars must be shorter than $9 \mathrm{~m}$ when its initial velocity is $30 \mathrm{~km} / \mathrm{h}$.

So, in the first case, the maximum $D_{\min 1}$ is $19+5=24 \mathrm{~m}$; in the second case, the maximum $D_{\min 1}$ is $21+5=26 \mathrm{~m}$ and in the third case the maximum $D_{\min 1}$ is $9+5=14 \mathrm{~m}$.

4.2.2. Theoretical Minimum Safety Legibility Distance. The theoretical minimum safety legibility distance refers to the safe braking distance when the driver fully concentrates on driving, finds the distress at the first time, and decelerates immediately from $v$ to $0 \mathrm{~km} / \mathrm{h}$.

According to normal driving behaviors, $D_{\min 0}$ equals the sum of the distance vehicle runs during the drivers' perception-reaction time $t_{r}$ and the safe distance between vehicles $d$. Perception-reaction time of the driver $t_{r}$ is as follows:

$$
t_{r}=t_{1}+t_{2}
$$

where $t_{1}$ is perception reaction time, $0.3-0.5 \mathrm{~s}$, and $t_{2}$ is driving behavior operation time, $0.3-0.5 \mathrm{~s}$ :

$$
t_{b}=-\frac{v}{a}
$$

$d_{r}$ is the traveling distances of the vehicle when the driver responses to the pavement distress:

$$
d_{r}=\left(t_{1}+t_{2}\right) \cdot v .
$$

And the traveling distance of the vehicle during the brake can be shown in formula (5):

$$
d_{b}=-0.5 \cdot a \cdot t_{b}^{2} .
$$


TABle 3: $D_{\min s}$ in different speed conditions.

\begin{tabular}{lcccc}
\hline Number & $v(\mathrm{~km} / \mathrm{h})$ & $v(\mathrm{~m} / \mathrm{s})$ & Academic $D_{s}(\mathrm{~m})$ & Recommended $D_{s}(\mathrm{~m})$ \\
\hline 1 & 20 & 5.56 & 20.51 & 25 \\
2 & 30 & 8.33 & 27.06 & 30 \\
3 & 40 & 11.11 & 34.75 & 35 \\
4 & 50 & 13.89 & 43.58 & 45 \\
5 & 60 & 16.67 & 53.55 & 55 \\
6 & 70 & 19.44 & 64.67 & 65 \\
7 & 80 & 22.22 & 76.93 & 80 \\
8 & 90 & 25.00 & 90.32 & 95 \\
9 & 100 & 27.78 & 104.87 & 105 \\
\hline
\end{tabular}

Note: the mantissa of recommended $D_{s}$ takes an integer multiple of 5 .

Put formula (4) into formula (6):

$$
d_{b}=-0.5 \cdot \frac{v^{2}}{a}
$$

Then

$$
\begin{aligned}
D_{\min 0} & =d_{r}+d_{b}+d \\
& =\left(t_{1}+t_{2}\right) \cdot v-0.5 \cdot \frac{v^{2}}{a}+d .
\end{aligned}
$$

4.2.3. Actual Minimum Safety Legibility Distance. Influenced by the driving condition, the drivers' psychological and physiological state, the drivers' attention, and the drivers' dynamic vision, the actual $D_{d}$ is larger than $D_{\min 0}$.

If $D_{d}<D_{\min 0}$, it is danger; while $D_{d} \geq D_{\min 0}$, it is safe. Then the safety condition can be concluded as follows:

$$
0.9004 D_{s}-0.1968 v-4.7645 \geq v \cdot t_{r}-0.5 \frac{v^{2}}{a}+d .
$$

Take sedan car as an example, when, in emergency, $t_{r}=$ $1.0 \mathrm{~s}, a=-7.5 \mathrm{~m} / \mathrm{s}^{2}$, and $d=5 \mathrm{~m}$. Put these parameters into formula (9); then we can get

$$
D_{s} \geq 0.074 v^{2}+1.3292 v+10.8446 .
$$

When the equal sign is tenable in formula (10) $D_{s}$ becomes the actual minimum safe static legibility distance $D_{\min s}$ :

$$
D_{\text {mins }}=0.074 v^{2}+1.3292 v+10.8446 \text {. }
$$

4.2.4. Case Study. The range of design speed of the urban road in China is $20 \sim 80 \mathrm{~km} / \mathrm{h}$; and then, the values of $D_{\min s}$ in different speeds can be calculated by formula (11), and the results are shown in Table 3.

It can be found that the value of $D_{s}$ gradually increases as the speed increases when compared with Tables 2 to 3 . When the value of $v$ reaches $100 \mathrm{~km} / \mathrm{h}, D_{s}$ reaches $105 \mathrm{~m}$, which is much longer than normal braking distance when $v=100 \mathrm{~km} / \mathrm{h}(50 \mathrm{~m})$. The two main reasons are (1) the driver failed to detect the pavement distress in time; (2) there is a delay between the drivers' identification, reaction, and the operation.

Driving safety is not only associated with vehicles but also associated with the drivers' reaction characteristics and operation skills. Therefore, we need to be aware of the possibility that the driver may not be able to find the distress in time and certain observation time and space are necessary.

Data in Table 3 shows that, in a road section where limit speed is $60 \mathrm{~km} / \mathrm{h}$, if the static legibility distance $D_{s}$ is less than $55 \mathrm{~m}$, it will be susceptible to accidents.

In addition, according to the inquiring survey on drivers in the condition that there is no need to brake when pavement distress is noticed, when $t<3 \mathrm{~s}$, drivers will react to the pavement distress in haste and it is prone to accidents, when $t>4 \mathrm{~s}$, drivers can deal with the information better, and when $t>5 \mathrm{~s}$, drivers can take the information in stride.

\section{Conclusions}

Identification of road information is the premise of the driving safety. Pavement distress is taken as research object in this paper and legibility distances in different conditions are studied; the main conclusions are as follows.

(1) Concepts of static legibility distance $\left(D_{s}\right)$ and dynamic legibility distance $\left(D_{d}\right)$ of pavement distress are put forward to describe the legibility of the pavement distress. And the relation between $D_{s}$ and $D_{d}$ is revealed.

(2) Safety legibility distance is analyzed from the aspects of minimum safety distance, theoretical minimum safety legibility distance, and actual minimum safety legibility distance. Relation between speeds, braking performance, and the minimum safety legibility distance is confirmed. And the recommend static legibility distances in different speed conditions are put forward.

One of the shortcomings of this paper is that the basic data in this paper is collected in urban road where the driving condition differs significantly from the highway; therefore the application in highway still needs to be verified. 


\section{Conflict of Interests}

The authors declare that there is no conflict of interests regarding the publication of this paper.

\section{Acknowledgment}

This research was financed by the National Natural Science Foundation of China (nos. 51108137 and 51078113).

\section{References}

[1] Y. Bie, D. Wang, and X. Qu, "Modelling correlation degree between two adjacent signalised intersections for dynamic subarea partition," IET Intelligent Transport Systems, vol. 7, no. 1, pp. 28-35, 2013.

[2] Z. Liu, Y. Yan, X. Qu, and Y. Zhang, "Bus stop-skipping scheme with random travel time," Transportation Research C: Emerging Technologies, vol. 35, pp. 46-56, 2013.

[3] Y. Bie, D. Wang, and H. Qi, "Prediction model of bus arrival time at signalized intersection using GPS data," Journal of Transportation Engineering, vol. 138, no. 1, pp. 12-20, 2011.

[4] Y. Bie, Z. Liu, D. Ma, and D. Wang, "Calibration of platoon dispersion parameter considering the impact of the number of lanes," Journal of Transportation Engineering, vol. 139, no. 2, pp. 200-207, 2013.

[5] S. Kulanthayan, A. Razak, and E. Schenk, "Driver characteristics associated with child safety seat usage in Malaysia: a crosssectional study," Accident Analysis and Prevention, vol. 42, no. 2, pp. 509-514, 2010.

[6] X. Qu, Q. Meng, and Z. Liu, "Estimation of number of fatalities caused by toxic gases due to fire in road tunnels," Accident Analysis \& Prevention, vol. 50, pp. 616-621, 2013.

[7] S. Vardaki, "Investigation of actual and perceived behavior of older drivers on freeways," Transportation Research Record, no. 2078, pp. 41-48, 2008.

[8] Y. Wang, G. Xu, and H. Bai, "Operating speed based alignment consistency evaluation using driving simulator: case studies from Taigan freeway in Jiangxi, China," PROMET-Traffic \& Transportation, vol. 25, no. 1, pp. 23-31, 2013.

[9] D. A. Grivas and Y.-C. Shen, "Fuzzy set approach for pavement damage assessments," Civil Engineering Systems, vol. 8, no. 1, pp. 37-47, 1991.

[10] Y.-G. Wang, K.-M. Chen, and L.-W. Hu, "Killer tailgating: recommendation of traveling intervals between consecutive motor vehicles for rear end collision avoidance," The Arabian Journal for Science and Engineering, vol. 37, no. 3, pp. 619-630, 2012.

[11] J. A. Prozzi and F. Hong, "Optimum statistical characterization of axle load spectra based on load-associated pavement damage," International Journal of Pavement Engineering, vol. 8, no. 4, pp. 323-330, 2007.

[12] K. M. Khan, "Development of pavement Distress Identification Manual for Motorway (M-2) Pakistan," in Proceedings of the 4th International Gulf Conference on Roads, pp. 865-873, November 2008.

[13] M. A. Karan, R. Haas, and R. Kher, "Effects of Pavement Roughness on Vehicle Speed," Transportation Research Record, no. 602 , pp. 122-127, 1976.

[14] R. Gallegos López, A. Mendoza Díaz, and A. Velázquez Salas, "Effect of the regularity of the pavement on traffic capacity on freeways and multilane highways in Mexico," Carreteras, vol. 4, no. 148 , pp. 35-47, 2006.

[15] S. Chandra, "Effect of road roughness on capacity of two-lane roads," Journal of Transportation Engineering, vol. 130, no. 3, pp. 360-364, 2004.

[16] B.-E. Johnnie and F. Neil, "Extent of capacity loss resulting from pavement distress," Proceedings of the Institution of Civil Engineers: Transport, vol. 158, no. 1, pp. 27-35, 2005.

[17] M. Vaziri, "Traffic behavior during highway maintenance and rehabilitation," in Proceedings of the 4th International Conference on Road \& Airfield Pavement Technology, pp. 1116-1120, 2002.

[18] T. Tronsmoen, "Differences between formal and informal practical driver training as experienced by the learners themselves," Transportation Research Part F, vol. 14, no. 3, pp. 176-188, 2011.

[19] W. Yonggang, L. Linchao, L. Feng, and H. Peng, "Professional drivers' views on risky driving behaviors and accident liability: a questionnaire survey in Xining, China," Transportation Letters, vol. 6 , no. 3, pp. 126-135, 2014. 


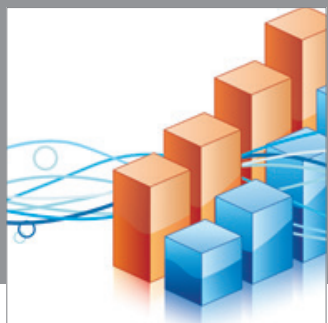

Advances in

Operations Research

mansans

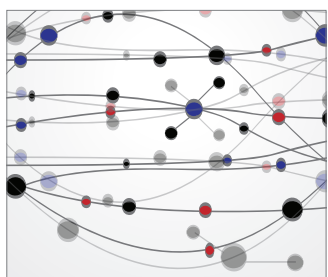

The Scientific World Journal
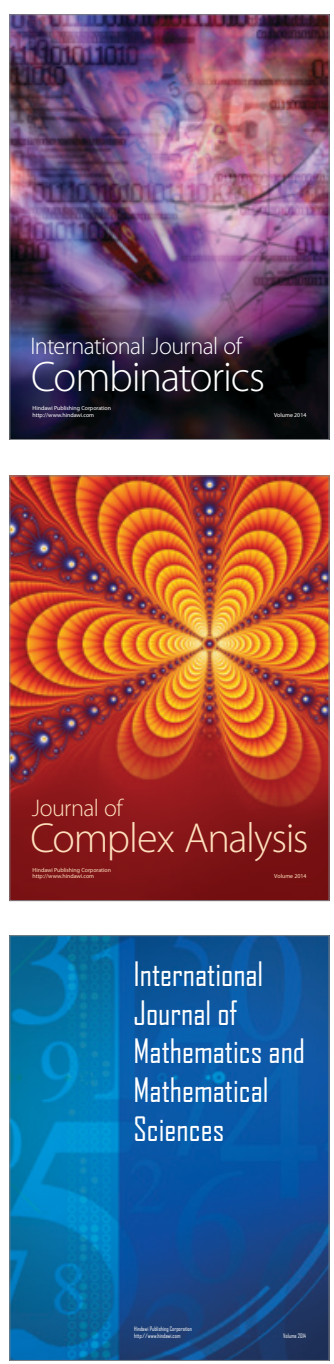
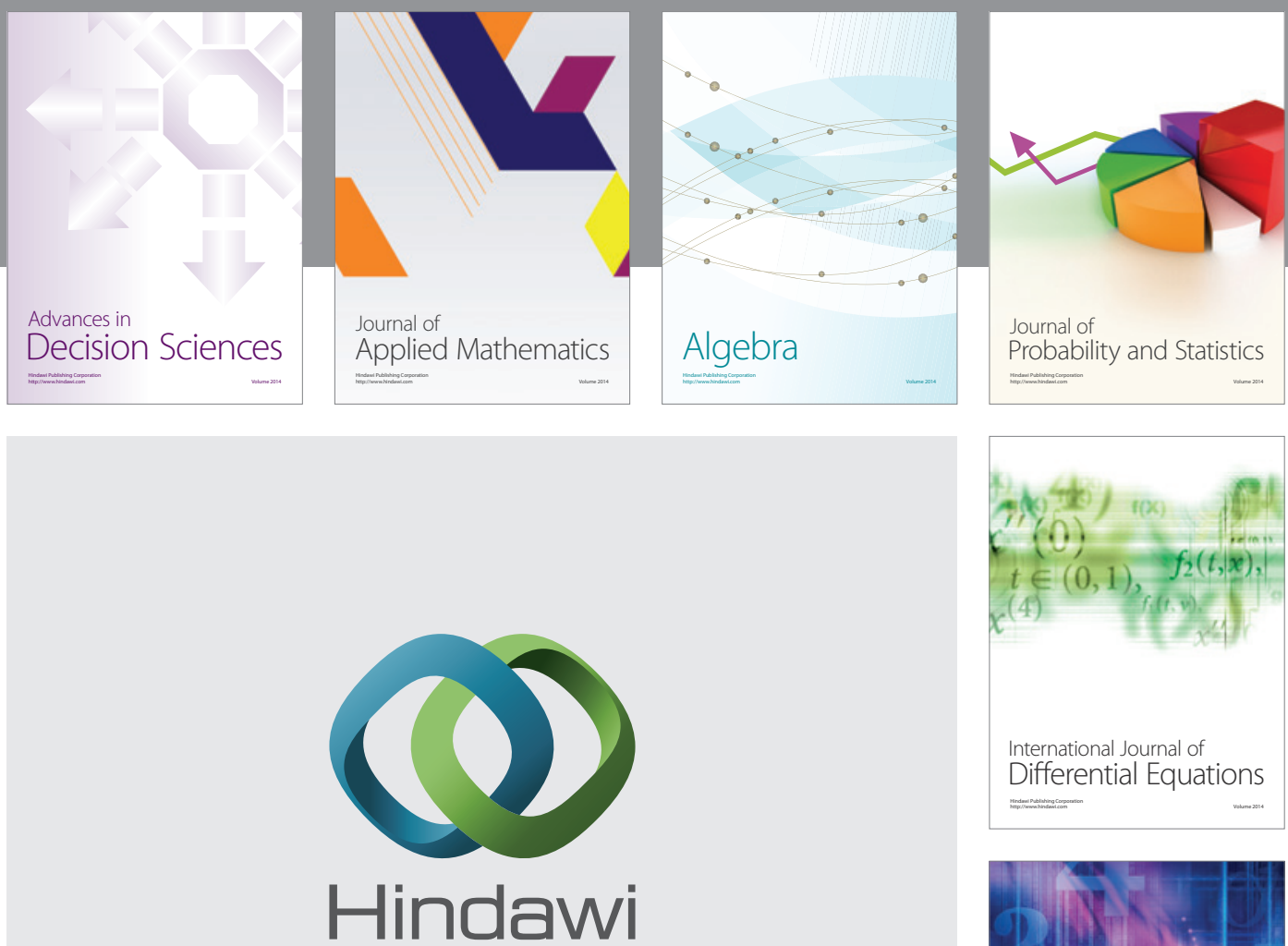

Submit your manuscripts at http://www.hindawi.com
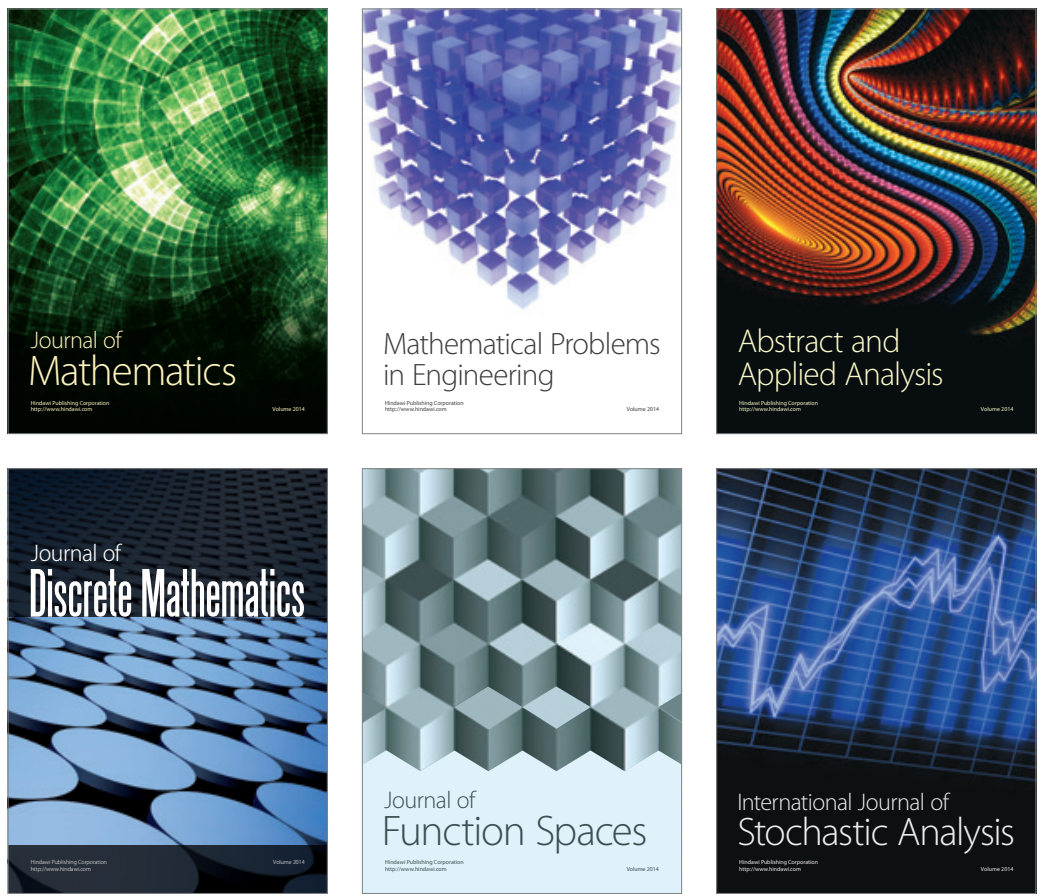

Journal of

Function Spaces

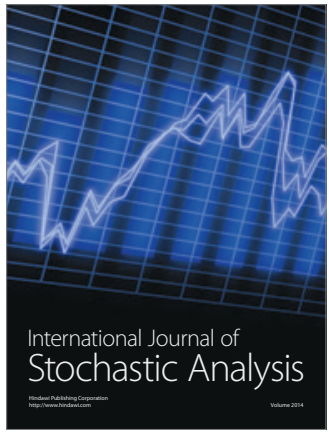

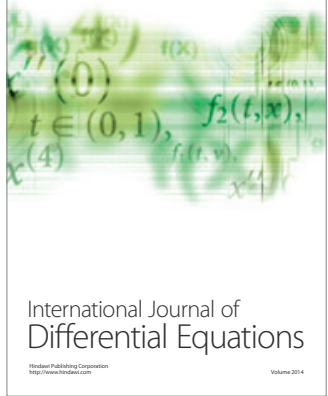
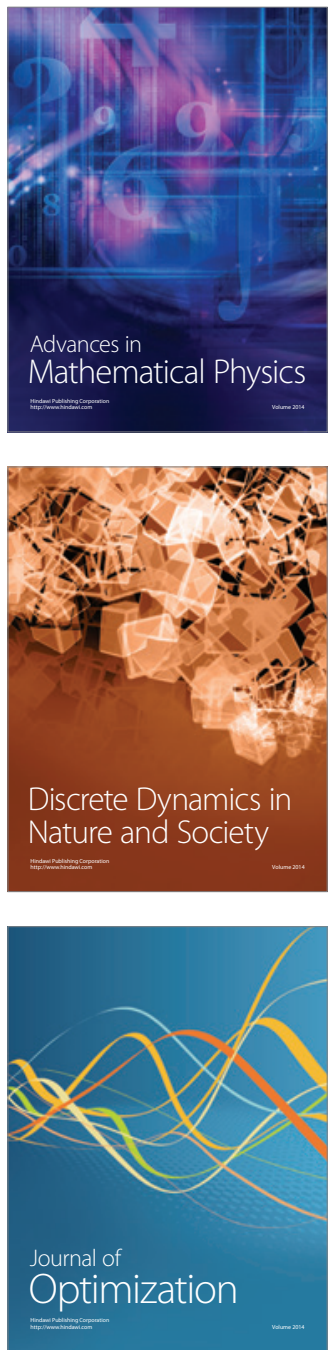